\title{
THE FIRST DAY OF CLASS
}

\author{
HOW SHOULD INSTRUCTORS USE CLASS TIME?
}

\author{
Sal Meyers, Simpson College \\ Brian C. Smith, Graceland University
}

Students and instructors rated first-day class satisfaction and completed scales assessing the time that instructors spent on introductions, course policies, procedures, and course content. For students, interest on or before the first day, and for faculty, excitement and confidence in students' abilities, strongly predicted satisfaction on the first day. Student and instructor satisfaction also were positively associated with time devoted to hows and whys, content, and introductions. Findings contradict previous empirical studies of student satisfaction but are consistent with faculty development recommendations.

Instructors are often advised to make sure the first day of class goes well (Clement, 2007; Lang, 2008) because the impressions students form on that day can have a lasting impact on satisfaction with the instructor, their motivation, and their performance throughout the semester (Wilson $\&$ Wilson, 2007). Given the assumption that what instructors do on the first day of class is important, what should instructors do?

One way to answer that question is to ask students what they consider to be most effective on the first day of class. Perlman and McCann (1999) asked students open-ended questions regarding the "most useful things a faculty member can do during a first class meeting" and the students' "pet peeves about what faculty do during a first class meeting" (p. 277). Students were most likely to list as useful activities reviewing the syllabus and course expectations; receiving information regarding assignments, exams, and grading; and having the instructor introduce himself or herself. Despite the tendency for published advice to recommend the use of icebreakers (McGlynn, 2001, offers an entire chapter on this 
topic), students more often listed icebreakers as a pet peeve than as something that works well. They also listed as pet peeves poor use of class time (for example, including noncrucial information and reading the syllabus aloud) and the instructor's beginning to teach course content.

Based on what students said they liked and disliked in Perlman and McCann's (1999) study and a replication by Henslee, Burgess, and Buskist (2006), Wilson and Wilson (2007) randomly assigned students to a positive or a negative first day of class. Students in the positive first-dayof-class condition left early after viewing a fifteen-minute video of the professor reviewing the syllabus in a friendly manner. Students assigned to the negative first-day-of-class condition viewed a video of the professor reviewing the same syllabus but without any emotional tone, then learned course content by watching a film and received a homework assignment about the film. Wilson and Wilson found not only that the students with the positive first-day experience rated the course and professor more positively than students with the negative first-day experience, but also that those students reported greater motivation and received better course grades at the end of the semester.

Based on the findings of these three studies (Henslee et al., 2006; Perlman \& McCann, 1999; Wilson \& Wilson, 2007), an instructor deciding what to do on the first day of class would likely opt to review the syllabus in a friendly manner, avoid icebreakers and introductions, avoid teaching course content, and let class out early. In contrast, advice from faculty developers suggests using icebreakers and introductions and teaching some course content, or at least having a meaningful discussion of the course objectives (Davis, 2009; Lang, 2008; McGlynn, 2001; McKeachie \& Svinicki, 2006; Nilson, 2003).

\section{The Student and Faculty Studies}

The studies we present here seek to determine whether the advice of faculty developers or the advice based on student preferences is associated with greater satisfaction with the first day of class. The first two studies focus on student perceptions and the third one on instructor perceptions. Because people are often not able to accurately describe the true causes of their behavior (Nisbett \& Bellows, 1977), rather than asking people to identify the things that increase their satisfaction with the first day of class, we asked participants to report how much time the instructor spent on specific activities and then to report how satisfied they were with the first day of class overall. 


\section{Study 1}

To examine which instructor behaviors are associated with a good first day of class, we asked students to indicate what happened on the first day of class and report their satisfaction with that first day.

\section{METHOD}

On the second day of the semester, students at a small midwestern liberal arts college were invited by e-mail to complete an anonymous online questionnaire about the first day of class in one of their courses. In order to increase the variability of students' responses, students were randomly assigned to complete the survey about a course that was the best, the worst, or the most recent of the various first days of class they had attended that spring.

The 164 respondents consisted of 37 men, 126 women, and 1 person who did not indicate gender. Respondents were fairly equally distributed across year in college: 23.8 percent were first-year students, 23.8 percent were sophomores, 30.5 percent were juniors, and 22.0 percent were seniors. The mean age of the respondents was 20.14 years $(S D=2.51)$.

Students indicated how much time the instructor spent on introductions, explaining how and why the course would be taught the way it would, course policies, and course content. Respondents were asked, "How much time did the instructor spend on" each item on a scale from 1 (no time) to 9 (a great deal of time). Time spent on introductions was assessed with a five-item measure that had adequate internal reliability (Cronbach's alpha $=.79$ ). The five items were introducing himself or herself, having students meet each other, starting to learn students' names, having students provide information about themselves in writing, and having students provide information about themselves in an activity or discussion. Time spent explaining the hows and whys of the course was assessed with a five-item measure that had adequate internal reliability (Cronbach's alpha $=.85$ ). These five items were discussing course objectives, discussing how the course would be taught, discussing why the course would be taught that way, discussing why the course material was important to learn, and indicating how to study for the course. Time spent on course policies was assessed with a single item: "Reviewing course rules and policies (for example, penalties for late work and academic honesty)." The last measure was a single item asking about time spent on "teaching course content."

Students' interest in taking the course was assessed with a three-item measure that demonstrated adequate internal reliability (Cronbach's 
alpha $=.73)$. Participants were asked to rate the extent to which "interest in the topic" and "interest in taking a class from this instructor" influenced their decision to take the course on a scale from 1 (not at all) to 7 (strongly influenced). Participants were also asked to indicate how motivated they were to learn in this class on a scale from 1 (not at all motivated) to 7 (extremely motivated).

Students indicated their satisfaction with the first day of class by indicating the extent to which they agreed with each of nine items on a scale from 1 (strongly disagree) to 9 (strongly agree). These evaluative items included statements such as the following: "Overall I am satisfied with my experience during the first day of this class," "I have a good feeling about this instructor," and "The instructor offered rich and substantial course content on the first day." The internal reliability of this measure was strong (Cronbach's alpha $=.95$ ).

\section{RESULTS}

Students selected a wide variety of different courses to describe and evaluate. The courses were fairly evenly spread across first year (38.4 percent), sophomore ( 34.1 percent), and upper level (27.4 percent). When asked whether they had taken the course to fill one or more requirements, 43.4 percent indicated they took the course to fill a general education requirement, 19.4 percent indicated they took it for a minor, and 56.1 percent reported that they took it for a major (these numbers sum to more than 100 because a course could fill both a general education requirement and the requirement for a major or minor). Students' reports of approximate class size indicated that 27.6 percent of the courses were small (five to fifteen people), 53.4 percent were medium (twenty to thirty people), and 19 percent were large (thirty-five or more people). Consistent with the gender balance of the faculty as a whole, more students selected a course taught by a man ( 59.8 percent) than a woman ( 40.2 percent).

The more interested that students were in taking a course, the more satisfied they were with how the first day of that course went. In fact, as can be seen in Table 11.1, student interest was the variable most strongly correlated with student satisfaction.

Instructors' use of time was also related to students' satisfaction with the first day of the course. Greater student satisfaction was associated with the instructor's spending more time on the hows and whys of the course, course content, and introductions. Time spent reviewing rules and policies was not related to student satisfaction. Contrary to the claim that having class meet for the entire time is a mistake (Wilson $\&$ Wilson, 2007), the proportion of the possible class time that the course met on the first day was also not related to student satisfaction. Having class 
Table Ir.I Study 1: Intercorrelations for Student Satisfaction with the First Day of Class, Student Interest in the Course, and How the Instructor Used Time on the First Day

\section{SI THW TI TC TRP PCM}

Student satisfaction with the

first day of class

$.62^{* * *} .47^{* * *} .18^{*} \quad .25^{* *} \quad .10 \quad .04$

Predictor variable

Student Interest (SI)

$-\quad .21^{* *} .05 \quad .16^{*} \quad-.02 \quad .09$

Time on Hows and Whys

$-\quad .42^{* *} .17^{*} \quad .47^{* *}-.004$ (THW)

Time on Introductions (TI)

$-\quad .04 \quad .30 * * * 08$

Time Teaching Content (TC)

$-\quad .05 \quad .29^{* * *}$

Time on Rules and Policies

(TRP)

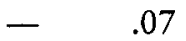

Proportion of Possible Time

Class Met (PCM)

Note: ${ }^{* *} p<.001 ;{ }^{* *} p<.01 ;{ }^{*} p<.05$.

meet for most or all of the class period on the first day appears to be the norm at this small liberal arts college: on average, courses met for 81 percent of the possible class time, and half of the courses met for at least 91 percent of the possible time.

Given that four variables were related to student satisfaction, we used regressions to determine which of these variables are related to student satisfaction when controlling for the others. We conducted a stepwise regression using student satisfaction as the dependent variable, and as predictor variables, we used the four ways instructors spent time on the first day and the proportion of time that classes met. Student interest in the course and the amount of time the instructor spent on the hows and whys of the course contributed to the prediction of student satisfaction even when controlling for the other variables. Together student interest in the course and time spent on hows and whys account for 50.1 percent of the variance in student satisfaction with the first day of class: $F(2,161)$ $=80.87, p<.001$.

\section{DISCUSSION}

The more time the instructor spent discussing the hows and whys of the course, the greater was the students' satisfaction with the first day. This result complements Bain's (2004) finding that the best college teachers 
plan their courses by first focusing on the big questions-the overall purpose of the course. Of the thirteen sets of questions that Bain identifies to guide instructors through the process of planning a course, all but one include the word how.

Student interest in the course is also a significant predictor of increased student satisfaction with the first day of class. This finding is consistent with the argument that students' prior interest in the course has important consequences for their evaluations of the first day of class; however, it is also consistent with the argument that a strong first day of class increases student interest in the course.

\section{Study 2}

Because all the data in study 1 were collected simultaneously, we have no way of knowing whether students' interest in the course reflected their prior interest or whether their interest was influenced by the activities on that first day. We therefore conducted a longitudinal study in which students reported their interest in the course before the first day of class and then completed a survey similar to that in study 1 just after the first day of class.

\section{METHOD}

One week prior to the start of the semester, students at two small midwestern colleges were invited to participate in a survey of their interest in each of the classes for which they were registered. After the first day of class, these same students were invited to complete a survey about the first day of class in one of their courses as was done in study 1. Fortyone students (eight men and thirty-three women) completed both surveys.

Students were asked to rate their courses on the following three items on a scale from 1 (strongly disagree) to 7 (strongly agree): (1) "I am interested in the topic of this course," (2) "I want to learn the content taught in this course," and (3) "I am looking forward to taking this course." The items were highly correlated with each other and thus were combined into two overall interest scores: one completed before the first day of class and one completed after the first day of class. The measure showed strong internal reliability at both times (alpha $=.92$ before the first day of class, alpha $=.90$ after the first day of class).

Students indicated their satisfaction with the first day of class on the same scale used in study 1 . They noted how time was spent on the first day using the same measures as those in study 1 except for the measure 
used to assess time spent on introductions. The two items from study 1 that asked about time spent having students provide information about themselves were combined, and an additional item asking about time spent on icebreakers was added.

\section{RESULTS AND DISCUSSION}

Consistent with study 1 , we found that the more interested students were in taking a course, the more satisfied they were with the first day of the course. As can be seen in Table 11.2, this is true both when student interest is measured before the first day of class and after the first day. The strength of the correlation between interest and satisfaction is stronger when interest is measured after the first day than when interest is measured before the first day $(t(38)=2.25, p<.05)$. A stronger correlation between interest and satisfaction after the first day of class than before it indicates that interest levels after the first day are better predictors of satisfaction; however, it does not mean that interest in the course was greater after the first day than before it. In fact, the average level of student interest

Table I I.2 Study 2: Intercorrelations for Student Satisfaction with the First Day of Class, Student Interest in the Course, and How the Instructor Used Time on the First Day

\section{$\begin{array}{llllll}\text { SI-1 } & \text { SI-2 } & \text { THW TI } & \text { TC } & \text { TRP } & \text { PCM }\end{array}$}

Student satisfaction with the first day

$$
\begin{array}{rrrrr}
.56^{* * *} .77^{* * *} .39 * * & .23 & .36 * .18 & -.10 \\
.60^{* * *} .23 & .07 & .09 & .13 & -.21
\end{array}
$$

Student interest prior to the first day (SI-1)

Predictor variable

Student Interest After First Day (SI-2)

$$
.26+.041 \quad .19 \quad .10 \quad-.18
$$

Time on Hows and Whys

(THW)

$.35^{*} \quad .30^{*} .66^{* * *}-.21$

Time on Introductions (TI) $\begin{array}{lll}-.23 & .13 \quad .02\end{array}$

Time Teaching Content (TC) $.10 \quad .25$

Time on Rules and Policies (TRP)

Proportion of Possible Time

Class Met (PCM)

$$
\text { Note: }{ }^{* *} p<.001 ;{ }^{*} p<.01 ;{ }^{*} p<.05 ;+p=.052 \text {. }
$$


was the same before the first day $(M=5.83, S D=1.33)$ compared to after the first day $(M=5.71, S D=1.27), t(40)=.67, n s$.

These results suggest that student interest is more likely a cause of student satisfaction on the first day than an effect of it. Even when student interest is measured before the first day of class, this interest predicts student satisfaction with that day. This relationship between student interest and student satisfaction can thus not be a function of instructor behaviors' increasing student interest. This should not be interpreted to mean that nothing the instructor does can change student interest; it simply means that student interest, independent of anything the faculty member does, is a good predictor of student satisfaction on the first day of class.

Instructors' use of time predicted students' satisfaction with the first day of the course (Table 11.2). Consistent with the findings of study 1 , greater student satisfaction was associated with the instructor spending more time on the hows and whys of the course and more time on course content. Also consistent with study 1, time spent reviewing the rules and policies of the course was not related to student satisfaction.

As in study 1 , we conducted a stepwise regression using student satisfaction as the dependent variable and student interest, the four ways instructors spent time on the first day, and the proportion of time that classes met as possible predictor variables. In this analysis, we used the measurement of student interest done prior to the first day of class so that we could be sure that none of the other variables had a causal influence on student interest. Whereas in study 1 we found that student interest and time spent on hows and whys contributed to the prediction of student satisfaction, in study 2 we found that student interest, time spent teaching course content, and time spent on introductions significantly predicted student satisfaction over and above the other variables in the equation. Together these three variables (interest, content, and introductions) accounted for $\mathbf{4 8 . 5}$ percent of the variance in student satisfaction with the first day of class: $F(3,37)=11.61, p<.001$.

The discrepancy between the predictors that entered the regression equations in study 1 versus study 2 may be a result of minor differences in the correlation coefficients calculated in the two studies. The more important finding is that instructor behaviors predict student satisfaction over and above student interest. All three instructor behaviors are correlated to student satisfaction at about the same level (in the low 0.3 range). Furthermore, the amounts of time spent on those behaviors tend to be correlated with each other at about the same level; thus, instructors who spend time on hows and whys also tend to spend time teaching content and doing introductions. 
Study 3

Another way to examine which instructor behaviors are associated with a good first day of class is to ask instructors themselves. As we did with the students, rather than asking instructors to indicate which things they think are particularly effective, we asked them to describe what they did on the first day of a specific class and then to report how well they thought that particular class went.

\section{METHOD}

On the second day of the semester, instructors at two small midwestern colleges were invited to complete a survey about the first day of class in one of their courses. To increase the variability of the quality of the courses, instructors were randomly assigned to consider the best first day of class that semester or the worst first day. The survey was completed by eighty-four instructors (forty-four men and forty women) who varied in terms of faculty rank: 15.5 percent were instructors, 39.3 percent were assistant professors, 14.3 percent were associate professors, and 31.0 percent were full professors. The courses they taught were roughly the same size as those described by students in the previous studies: 34.5 percent had around five to fifteen students, 40.4 percent had twenty to thirty students, and 25.0 percent had thirty-five or more students. Most of the courses were taught as a requirement for a major or minor (78.6 percent), but almost half filled a general education requirement (46.4 percent).

Instructors were asked to indicate their excitement about teaching the course on a scale from 1 (not at all excited) to 7 (extremely excited). They were also asked to rate the extent to which they agreed with the statement, "I feel confident in my students' ability to do well in this class," on a scale from 1 (strongly disagree) to 7 (strongly agree).

Instructors rated their satisfaction with the first day of class on a nineitem scale similar to that completed by students in studies 1 and 2 (Cronbach's alpha $=.86$ ). Instructors rated how much time they spent on introductions, course policies, explaining how and why the course would be taught the way it would, and course content using the same measures as described in study 2 .

\section{RESULTS AND DISCUSSION}

Instructors' satisfaction with the first day of class was strongly related to their excitement about teaching the class and confidence in their students' abilities (Table 11.3). The more excited instructors were about teaching 
Table I I.3 Study 3: Intercorrelations for Instructor Satisfaction with the First Day of Class, Instructor Excitement in the Course, Instructor Confidence in Students, and How the Instructor Used Time on the First Day

$$
\text { IEC ICS THW TI TC TRP PCM }
$$

Instructor satisfaction

with the first day $.63^{* * *} .67^{* * *} .28^{*} \quad .34^{* *} \quad .25^{*} \quad .03 \quad .37^{* * *}$

Predictor variable

Instructor Excitement

About the Course

(IEC)

$$
\begin{array}{rrrrr}
.54^{* * *} .20 & .13 & .18 & -.05 & .31^{* *} \\
& .22^{*} & .21 & .30^{* *}-.01 & .17 \\
& .33^{* *} & .10 & .45^{* * *} & .10 \\
& & -.14 & .23^{*} & -.10
\end{array}
$$

Instructor Confidence in Students (ICS)

Time on Hows and Whys (THW)

Time on Introductions

Time Teaching Content (TC)

Time on Rules and

Policies (TRP)

Proportion of Possible

Time Class Met (PCM)

$$
\text { Note: }{ }^{* *} p<.001 ;{ }^{*} p<.01 ;{ }^{*} p<.05 \text {. }
$$

the class, the better they thought the first day went. Similarly, the more confidence they had in their students' ability to do well in the course, the greater was their first day satisfaction. Faculty excitement about the course is thus related to faculty satisfaction with the first day the same way that student interest is related to student satisfaction.

The same instructor uses of class time that were related to student satisfaction in studies 1 and 2 were also related to instructor satisfaction in this study. The more time the instructor spent discussing the hows and whys of the course, on introductions, and on teaching course content, the more satisfied they were with the first day of class. Although we have no way of testing whether instructor satisfaction is related to student satisfaction, the fact that the same instructor behaviors are associated with both student and instructor satisfaction suggests that instructors and students share similar perceptions of the first day of class. Future research should test whether student and instructor satisfaction are related. 
To examine how well the instructors' use of time predicted instructors' satisfaction with the first day of class, we conducted a stepwise regression using satisfaction as the dependent variable and instructor excitement, the ways instructors used class time, and the proportion of class time used as the predictor variables. Instructor satisfaction with the first day of class was best predicted by a combination of three variables: excitement about teaching the course, time spent on introductions, and time spent teaching course content. Together these three variables predicted 52 percent of the variance in instructor satisfaction: $F(3,75)=29.73, p<.001$.

\section{Discussion}

What instructors do on the first day of class is related to both students' and instructors' satisfaction with that day. Students in previous studies have identified pet peeves that include teaching course content on the first day of class, using icebreakers and introductions, and having the class meet the entire class period (Perlman \& McCann, 1999). In contrast, the studies we present here consistently showed that teaching content and doing introductions are associated with greater student and instructor satisfaction with the first day of class. Furthermore, the length of time the class meets is unrelated to students' satisfaction and positively related to instructors' satisfaction with the first day.

Why does this discrepancy between previous research and our findings exist? One possibility is that the previously published studies (Henslee et al., 2006; Perlman \& McCann, 1999) asked students to report about the first day of class in general rather than to evaluate the first day of a specific class. Students may in fact dislike learning course content on the first day of class, but they may still find that the first day of class goes better when content is taught. Alternatively, students may have in mind one or two particularly poor first days of class in which the instructor spent the entire class period doing icebreakers or lecturing on course content.

Another possible explanation for the discrepancy is that the previous studies were conducted at large public universities, whereas our studies were conducted at two private colleges, each with fewer than fifteen hundred undergraduates. Perhaps previous research findings are more appropriately generalized to larger institutions, and our findings are more appropriately generalized to smaller institutions. Future research should compare how students at large versus small institutions respond to various approaches to the first day of class.

Whereas the findings of these three studies are largely inconsistent with previous research on student preferences regarding the first day of class, our 
findings are consistent with previously published advice from faculty developers. Numerous authors recommend that instructors spend time on the first day of class doing introductions or using icebreakers (Eifler, 2008; Lang, 2008; McGlynn, 2001; McKeachie \& Svinicki, 2006; Nilson, 2003). Consistent with this advice, we found that the more time instructors evoted to introductions, the greater was the students' and instructors' satisfaction with the first day of class. Similarly, many authors recommend teaching course content on the first day of class (Lang, 2008; McKeachie \& Svinicki, 2006; Nilson, 2003). We found that the more time instructors spent teaching course content, the greater was students' and instructors' satisfaction with the first day of class.

Our findings are also consistent with previous studies of specific firstday-of-class activities. Consider, for example, the reciprocal interview activity (Case et al., 2008; Hermann \& Foster, 2008; Hermann, Foster, \& Hardin, 2010) in which the instructor and students take turns interviewing each other about course-related topics. The instructor asks students to form groups to discuss the syllabus and determine answers to a handful of broad questions provided by the instructor. These questions focus the students on course objectives and the way in which the course will be taught, thus directs their attention to the hows and whys of the course. The time spent in small groups also provides students with an opportunity to introduce themselves to some of their classmates. The instructor then calls on one member of each group to give the group's response to the interview questions. Groups select a different representative to ask interview questions of the instructor on behalf of the group. This provides the instructor with the chance to introduce himself or herself to the students in response to the students' questions.

\section{Conclusion}

The results we report here have practical implications for how instructors can ensure that the first day of class goes well. Faculty developers are encouraged to share these findings with the instructors they serve. This could be done during new-faculty orientation sessions, with all faculty members in a faculty newsletter or a workshop, or during individual consultations when instructors discuss poor student course evaluations. Rather than doing what students say they want instructors to do (for example, avoid teaching content and letting class out early), instructors should be encouraged to follow the advice of instructors and faculty developers: make sure students get to know the instructor and one another, focus on the hows and whys of the course, and teach course content. 


\section{REFERENCES}

Bain, K. (2004). What the best college teachers do. Cambridge, MA: Harvard University Press.

Case, K., Bartsch, R., McEnery, L., Hall, S., Hermann, A., \& Foster, D. (2008). Establishing a comfortable classroom from day one: Student perceptions of the reciprocal interview. College Teaching, 56, 210-214.

Clement, M. C. (2007). Ten things to make the first day (and the rest) of the semester successful. Teaching Professor, 21(7), 1-3.

Davis, B. G. (2009). Tools for teaching (2nd ed.). San Francisco: Jossey-Bass. Eifler, K. (2008). Academic speed dating. Teaching Professor, 22(6), 8.

Henslee, A. M., Burgess, D. R., \& Buskist, W. (2006). Student preferences for first day of class activities. Teaching of Psychology, 33, 189-207.

Hermann, A. D., \& Foster, D. A. (2008). Fostering approachability and classroom participation during the first day of class: Evidence for a reciprocal interview activity. Active Learning in Higher Education, 9(2), 139-151.

Hermann, A. D., Foster, D. A., \& Hardin, E. E. (2010). Does the first week of class matter? A quasi-experimental investigation of student satisfaction. Teaching of Psychology, 37, 79-84.

Lang, J. M. (2008). On course: A week-by-week guide to your first semester of college teaching. Cambridge, MA: Harvard University Press.

McGlynn, A. P. (2001). Successful beginnings for college teaching: Engaging your students from the first day. Madison, WI: Atwood.

McKeachie, W. J., \& Svinicki, M. (2006). Teaching tips: Strategies, research, and theory for college and university teachers. Boston: Houghton Mifflin.

Nilson, L. B. (2003). Teaching at its best: A research-based resource for college instructors (2nd ed.). San Francisco: Jossey-Bass/Anker.

Nisbett, R. E., \& Bellows, N. (1977). Verbal reports about causal influences on social judgments: Private access versus public theories. Journal of Personality and Social Psychology, 35, 613-624.

Perlman, B., \& McCann, L. I. (1999). Student perspectives on the first day of class. Teaching of Psychology, 26, 277-279.

Wilson, J. H., \& Wilson, S. B. (2007). The first day of class affects student motivation: An experimental study. Teaching of Psychology, 34, 226-230. 